Al-Mohannadi, A. and Capel, S. (2007) Stress in physical education teachers in Qatar, Social Psychology of Education, 10 (1), 55-75

\title{
Stress in physical education teachers in Qatar
}

\author{
Ahmad Al-Mohannadi ${ }^{1}$ and Susan Capel $^{2}$ \\ 1 = Qatar University \\ $2=$ Brunel University
}

\begin{abstract}
Stress is an area of interest among researchers and practitioners in many fields - including teaching. Much of the research on causes of stress for teachers has focused on teachers in general; only a few studies have focused on physical education teachers. Although there have been a few studies of causes of stress for physical education teachers in the Middle East, no studies have been conducted on physical education teachers in Qatar. Thus, the purpose of this study was to identify causes of stress for physical education teachers in Qatar at the beginning and end of the school year as well as any changes over the course of the year. A second purpose was to try to explain any differences in causes of stress according to: gender; nationality; type of school; and amount of experience. Results showed that there were different causes of stress for different groups of teachers which could be related to different backgrounds and experiences and different roles and responsibilities in society as a result of different cultural and social expectations and environmental factors.
\end{abstract}

\section{INTRODUCTION}

Stress is an area of interest among researchers and practitioners in many fields - including teaching. Many studies over a period of time have found teaching to be a stressful occupation (see, for example, Dunham, 1976; Fejgin et al, 1995; Kyriacou and Sutcliffe, 1987a, b).

\section{Definitions of stress}

The study of stress stems from early work by Selye (1946, p.55), who described stress as 'the non-specific response of the body to any demand made on it to adapt'. Not all stress is damaging to the body; indeed, positive stress (eustress) is needed to promote physical growth. Eustress is usually associated with a moderate level of stress which motivates the person to achieve an 
optimum level of performance. What is a moderate level is different for each person. On the other hand negative or bad stress (distress) is damaging to the body.

Since then the word stress has generally been associated with negative effect; stress that is damaging to the body. For example, in relation to teacher stress, Kyriacou and Sutcliffe (1978, p.3) reported that "stress is a response syndrome mediated by an appraisal of threat to the teacher's self-esteem or well-being”. Kyriacou (1987, p.146) added that “Teacher's stress may be defined as the experience by a teacher of an unpleasant emotion, such as tension, frustration, anxiety, anger and depression, resulting from aspects of his work as a teacher". It is this definition that is adopted in this study.

\section{Theoretical underpinning}

Different definitions of stress are related to different theories of stress. There are many theories of stress in general as well as stress in teaching. In the Person-Environment (P-E) Fit theory (Lazarus, 1966; Lazarus \& Folkman, 1984) the core premise is that stress does not arise from a person or their environment separately, but rather from the interaction, or fit, between a person and their environment (see, for example, Caplan, 1987; Caplan \& Harrison, 1993; French et al, 1982; Harrison, 1978, 1985). A good fit between a person and the environment generally results in a person not being stressed. On the other hand, stress arises from the misfit between a person and the environment. Thus, the experience of stress is a result of a person's appraisal of a perceived imbalance between a teacher's perceptions of the demands of a specific situation and difficulty or inability to meet such demands in a particular situation where the perceived consequences are important. The fit or misfit may be due - at least in part, to the person's background and experiences and roles and responsibilities in society as a result of different cultural and social expectations and environmental factors. These may apply differentially to different groups of teachers.

The P-E Fit theory has been used in previous studies of teachers' stress (e.g., Abel \& Sewell, 1999; Brown \& Ralph, 2002; Pithers \& Fogarty, 1995; Reid \& Hinton, 1999; Smith \& Bourke, 1992; Storey \& Billingham, 2001; Wilson \& Hall, 2002).

\section{Causes of stress for teachers}

Selye (1946) identified the stimuli that create stress as "stressors". Others refer to these simply as causes of stress. A number of causes of stress for teachers have been identified over a period of time (see, for example, Abel \& Sewell, 1999; Adams, 2001; Blix et al, 1994; Borg et al, 1991; Brown \& Ralph, 1992, 2002; Cooper, 1996; Cooper \& Kelly, 1993; Dick \& Wagner, 2001; 
Dunham, 1984; Hart et al, 1995; Jones \& Fletcher 1999; Kyriacou, 1989; Kyriacou \& Sutcliffe, 1977, 1987a, b; Manthei \& Solman, 1988; Pithers \& Soden, 1998; Proctor, 1994; Punch \& Tuettemann, 1991; Quick \& Quick, 1984; Tollan, 1990; Travers \& Cooper, 1996; Trendall, 1989; Tuetemann \& Punch, 1990). These can be divided into those related to the person, those related to the job of teaching itself, and those related to the environment in which the teacher works. For example:

- the person, e.g. lack of professional satisfaction, professional problems, coping with change, self-esteem, emotional demands of teaching, being evaluated by others, personal perceptions and feelings, professional recognition needs, locus of control, dealing with colleagues;

- the job of teaching, e.g. role preparedness, class size (generally large classes), the pressure of the teacher's role, maintaining discipline, pupils' attitudes and behaviour, teaching pupils who lack motivation, non-participation by pupils, limited progress of pupils, pupil assessment; high pupil-teacher ratio, problems related to the curriculum, lack of non-contact time; and

- the working environment, e.g. low status of teaching, lack of respect for teachers, role conflict and role ambiguity, time pressures, heavy workload/workload out of proportion with salaries, management style, relationships with colleagues, administration and management, lack of support from managers, supervisory support and peer support, lack of effective communication, poor working environment, poor facilities, resource difficulties, relationships with parents and the wider community, work routine, societal attitude toward physical education, low/insufficient remuneration (including salaries, bonuses and allowances), lack of involvement in decision making, lack of support from the government; constant changes; lack of information about these changes; national curriculum; lack of relationship between teaching skill and promotion; social expectations

These causes of stress for teachers have largely been identified in studies in western, English speaking countries. Differences in other cultures may result in other cause of stress. For example, Al-farmawy (1994), Bukhet (1994), Ibrahim (1993), Khaleel (1999), Mohammed (2000) and Murad (1997) all found that causes of stress for physical education teachers in Egypt include: pupils' behaviour; problems related to the curriculum; school facilities; workload; time pressure; role conflict; work routine; low supervision; the relationship between the physical education teacher and school administration; lack of support from the school administration; lack of appreciation shown by school administration and parents; relations with colleagues; the profession's stress itself; lack of professional satisfaction; low status of physical education teaching; societal attitude toward physical education; low salary/inadequate income from teaching. 
In a study in Bahrain Al-Khalefa (1999) found the major causes of stress for physical education teachers to be: work conditions; salaries, bonuses and allowances; status of physical education; supervision; school facilities; workload; career development.

In summary, many causes of stress have been identified for teachers in general, including physical education teachers, although there are some causes specific to physical education teachers and some to teachers (including physical education teachers) in the Middle East. It would also be expected that there would be differences for other groups of teachers with different backgrounds and experiences which may result in them interacting differently with their environment.

\section{PURPOSE OF THIS STUDY}

Many researchers have studied stress in the last few decades; however, much of the research on causes of stress for teachers has focused on teachers in general; only a few studies have focused on physical education teachers. Although there have been a few studies of causes of stress for physical education teachers in the Middle East, no studies have been conducted on physical education teachers in Qatar. Thus, the purpose of this study was to identify causes of stress for physical education teachers in Qatar at the beginning and end of the school year as well as any changes over the course of the year. As there are likely to be broad differences between groups of teachers as a result of different backgrounds and experiences and different roles and responsibilities in society as a result of different cultural and social expectations and environmental factors which create a fit or misfit between different groups and the job of teaching, a second purpose was to try to explain any differences in causes of stress according to: gender; nationality; type of school; and amount of experience.

\section{METHODS}

\section{$\underline{\text { Participants }}$}

The sample for this study comprised male and female physical education teachers in elementary, preparatory and secondary schools in Qatar. The total number of physical education teachers in schools in Qatar is 293. At the first administration of the questionnaire, 240 questionnaires were given to physical education teachers (82\% of the total population), with 199 returned (82.9\% response rate). These comprised 113 male and 86 female teachers; 165 Qatari (99 male; 66 female) and 34 non-Qatari teachers (14 male; 20 female). At the second administration, questionnaires were given to 260 physical education teachers, with 202 returned $(77.6 \%$ response rate); 153 by teachers who had also answered the questionnaire at the first administration and 46 by teachers who only responded at the second administration of the questionnaire. One hundred 
and eleven of the responses, were from male and 91 from female teachers; 162 were from Qatari (92 male; 70 female) and 40 from non-Qatari teachers (19 male; 21 female).

The percentage of female teachers in primary schools is higher $(66.3 \%)$ than male teachers $(33.6 \%)$. In preparatory and secondary schools, however, the percentage of male teachers $(62.9 \%$ preparatory; $77.1 \%$ - secondary) is higher than the percentage of female teachers $(37.0 \%$ preparatory; 22.8\% - secondary). This reflects a gender-specific aspect of Qatari culture; that is, it is acceptable for females to teach boys up to the age of 11 . Thus, female teachers teach in both girls' and boys' primary schools. In preparatory and secondary schools, there is a higher percentage of male than female physical education teachers, not only because the overall number of male physical education teachers is greater, but also because boys have two physical education lessons per week whereas girls have one. The second lesson for boys is replaced for girls with one lesson per week of a subject called 'feminine education' in which they learn cooking and sewing.

Further, changes in educational development in Qatar - including changes to teacher training account for there being: (i) a higher percentage of non-Qatari (51.9\%) than Qatari (48.0\%) teachers with 10 and more years experience, but no non-Qatari teachers with less than six years experience; and (ii) a higher percentage of non-Qatari teachers in secondary (40.3\%) than in preparatory $(11.1 \%)$ or primary schools $(9.9 \%)$. The majority of non-Qatari teachers have been in Qatar since the beginning of the 1980s, when the number of Qatari physical education teachers was quite small. The Department of Physical Education at Qatar University opened in the early 1980s. The first graduates from this programme therefore have just over 20 years of experience. Thus, the majority of non-Qatari teachers are in the $32.2 \%$ who have 10 and more years experience. The main reason that a higher percentage of non-Qatari teachers teach at secondary schools is because the Department of Physical Education in the Ministry of Education and Higher Education believes that experienced physical education teachers should teach in secondary schools, and less experienced teachers should teach in primary and preparatory schools. Thus, teachers generally start their career in primary schools, then move to preparatory schools and finally to secondary schools. Thus, a higher percentage of less experienced physical education teachers - most of whom are Qatari in nationality, teach in primary and preparatory schools, and a higher percentage of teachers (many non-Qatari) with ten years and more experience teach in secondary schools.

\section{Instrument}

There was no instrument suitable for use in this study, therefore one was constructed. In constructing the questionnaire, possible causes of stress for physical education teachers were 
identified from a range of sources - including various questionnaires and papers and teachers themselves. The stress questions on a questionnaire developed by Kahleel (1999) was particularly influential in designing questions because it had been developed for use with physical education teachers in Egypt. Benefits of this questionnaire were: (a) the similarities in contexts - specifically: (i) the education system in Qatar is very similar to that in Egypt and the Qatari physical education curriculum was originally designed by an Egyptian and is similar to the Egyptian physical education curriculum; (ii) the religion in Egypt is the same as Qatar; and (iii) the culture in Egypt is very similar to Qatar; and (b) the questions were in Arabic, thus the meaning would not be lost by translating from another language into Arabic. This process resulted in a 54 item questionnaire, with responses to each statement being made on a 5-point Likert scale ranging from $5=$ definitely agree to $1=$ definitely disagree.

\section{$\underline{\text { Pilot study }}$}

The questionnaire was piloted with a sample of 19 physical education teachers in Qatar in the autumn term of the school year prior to the study being conducted.

\section{Procedure}

Following the required permission to conduct the study from the Ministry of Education and Higher Education, the first administration of the physical education teacher stress questionnaire took place in October/November, near the beginning of the school year in Qatar in September. The second administration took place in exactly the same way in May/June, near the end of the school year in Qatar.

Questionnaires were administered through personal delivery for two main reasons. First, the response rate is generally higher than for postal questionnaires. Second, a postal questionnaire would need to contain a copy of the written permission to conduct the study from the Ministry of Education and Higher Education. Such a letter was likely to be perceived by respondents as meaning completion of the questionnaire was not voluntary. Although this was likely to result in a high response rate, the researcher was concerned that due to the culture in Qatar teachers would perceive that a wrong answer may have implications for them personally, therefore they would respond to questions with answers that they thought would be acceptable to, or the 'right' ones for, the Ministry.

All schools in Qatar are single sex and - with the exception of female teachers teaching in boys' primary schools, all teachers are the same gender as the pupils in the school. Further, males are not allowed to enter girls' schools in Qatar. Therefore, this decision to personally deliver the 
questionnaires made it necessary to adopt two slightly different methods of data collection although the researcher attempted to keep the two data collections as similar as possible.

Questionnaires - along with an informed consent sheet, were distributed by hand to male teachers, by visiting each boys' school. Teachers were told that the completed questionnaire would be collected in a few days. A letter was written to the headmistress of each girls' school explaining the study and asking her to give the questionnaires and informed consent sheet to all physical education teachers following the enclosed instructions (these were the same as given to male teachers to ensure as much comparability in completion as possible). She was told that the researcher would collect the completed questionnaires in a few days. The covering letter to the headmistress, plus copies of the questionnaires, informed consent and instructions for each physical education teacher were taken to each girls' school and left with the security guard to give to the headmistress.

Although it is recognised that using two slightly different methods of data collection for men and women is not ideal, this was perceived to be the most appropriate way to distribute the questionnaires as it was anticipated that there would be less influence on responses than a postal survey. As far as is known, this was the first survey in Qatar in which male and female teachers perceptions have been compared, therefore despite its imperfections, it has enabled a comparison to be made between men and women.

\section{Validity and reliability}

Results of tests of validity at the second administration of the questionnaire showed that: for content validity correlation coefficients ranged between 0.54 and 0.19 (significant at 0.01 or 0.05), for all items except four; and for differential validity there were significant differences at 0.01 or 0.05 for all the items except nine - four of which were those also identified for content validity. These nine items were eliminated from analysis of the measure, resulting in a 45 item questionnaire. Tests of reliability identified an alpha coefficient of 0.93, and split-half measure between the first and the second part equal to 0.86 , with a probable coefficient for the bisection equalling 0.9277 . These results point to high validity and reliability of the questionnaire as a measure of the causes of stress for physical education teachers in Qatar.

\section{Data analysis}

The Statistical Package for the Social Sciences (SPSS) was used in the analysis of data. Factor analysis using extraction, principal component analysis and rotation, the Varimax method with Kaiser Normalisation, taking the average of the scores on the items that make up the factor, 
was conducted to condense the information contained in a number of questions into a smaller set of dimensions, with a minimal loss of information. The mean and standard deviation of the factors were found. T-test was used to find the difference in stress between male and female, Qatari and non-Qatari physical education teachers and the beginning and end of the school year. To find out the differences between physical education teachers in different types of school and with different amounts of experience, one way analysis of variance (ANOVA) was conducted.

\section{FINDINGS AND DISCUSSION}

Eight factors were identified as:

F1 problems with administration not appreciating physical teachers work ('lack of appreciation') (9 items);

F2 workload and responsibilities ('workload') (9 items);

F3 physical education curriculum ('curriculum') (6 items);

F4 low status of physical education as a subject ('low status') (5 items);

F5 salaries, bonuses and allowances ('remuneration') (3 items);

F6 poor school facilities ('facilities') (4 items);

F7 pupils' problems ('pupil problems') (6 items); and

F8 responsibilities for pupils' safety ('safety') (3 items).

These factors were used in further analysis of the data.

\section{Stress for all teachers}

Table 1 shows that the overall mean score of all teachers was slightly above the mid-point on the response scale ( $\mathrm{m}=3.33$ and 3.40 at the beginning and end of the school year, respectively). There was no significant difference between the total amount of stress at the beginning and end of the school year. Thus, overall, teachers' stress did not change during the year. Therefore, teachers who had high stress at the beginning of the year were likely to have high stress at the end of the year; likewise, teachers whose stress level was low at the beginning of the year were likely to experience low stress at the end of the year.

The factor which caused most stress for all teachers both at the beginning and end of the school year was 'pupil problems' ( $m=3.92$ and 3.90, respectively), followed by the 'curriculum' at the beginning of the school year $(\mathrm{m}=3.51)$ (ranked third at the end of the school year), and 'remuneration' at the end of the school year $(\mathrm{m}=3.57)$ (ranked fourth at the beginning of the school year). These factors have been identified in other studies that have examined causes of 
stress for teachers (e.g. Al-Khalefa, 1999; Khaleel, 1999; Mohammed, 2000; Punch \&Tuettemann, 1991).

The factor which caused least stress at the beginning of the school year was 'workload' (m $=2.82$ ) (ranked second lowest at the end of the school year), and at the end of the school year was 'lack of appreciation' ( $m=2.93)$ (ranked second lowest at the beginning of the school year).

'Workload' was the only factor on which there was a significant difference between the beginning and end of the school year (an increase from $\mathrm{m}=2.82$ to $2.94, \mathrm{t}=0.5$ ).

\section{Insert Table 1 about here}

\section{Differences between groups of teachers}

The next section gives results for different groups of teachers - by gender, nationality, type of school and amount of teaching experience.

At the beginning of the school year, the factor which caused most stress for both male and female teachers was 'pupil problems' ( $\mathrm{m}=4.12$ and 3.55, respectively), followed by 'low status' for male teachers $(\mathrm{m}=3.62)$ and the 'curriculum' for female teachers $(\mathrm{m}=3.38)$. The factor which caused least stress was 'workload' for male teachers $(\mathrm{m}=2.70)$ and 'lack of appreciation' for female teachers $(m=2.79)$. Further, male teachers had significantly more total stress $($ at 0.1$)$ than female teachers, as well as stress caused by: the 'curriculum' (at .05), 'low status' (at .01), 'facilities' (at .05) and 'pupil problems' (at .05); and significantly more stress was caused by 'workload' (at .01) for female than male teachers.

At the end of the school year, the factor which caused most stress for male and female teachers was 'pupil problems' $(\mathrm{m}=4.08$ and 3.71 , respectively), followed by 'facilities' for male teachers $(\mathrm{m}=3.57)$ and 'remuneration' for female teachers $(\mathrm{m}=3.65)$. The factor which caused least stress was 'workload' for male teachers $(\mathrm{m}=2.69)$ and 'lack of appreciation' for female teachers $(\mathrm{m}=2.92)$. There were no significant differences between male and female teachers in terms of total stress. However, significantly more stress was caused by 'low status' (at .01), 'facilities' (at .05), and 'pupil problems' (at .01) for male than female teachers; and more stress was caused by 'workload' (at .01) for female than male teachers.

At the beginning of the school year, the factor which caused most stress for both Qatari and non-Qatari teachers was 'pupil problems' ( $m=3.74$ and 4.22 respectively), followed by 'facilities' for Qatari teachers $(\mathrm{m}=3.52)$ and 'remuneration' for non-Qatari teachers $(\mathrm{m}=3.85)$. The factor which caused least stress was 'lack of appreciation' for Qatari teachers $(\mathrm{m}=2.90)$ and 'workload' 
for non-Qatari teachers $(\mathrm{m}=2.54)$. There were no significant differences between Qatari and nonQatari teachers in terms of total stress, but significantly more stress was caused by 'workload' (at .01 ) and 'facilities' (at .05) for Qatari than non-Qatari teachers; and significantly more stress was caused by ‘pupil problems' (at .01) and 'remuneration' (at .05) for non-Qatari than Qatari teachers.

At the end of the school year, the factor which caused most stress for Qatari teachers was 'pupil problems' ( $\mathrm{m}=4.86)$, followed by the 'curriculum' $(\mathrm{m}=3.56)$ and for non-Qatari teachers was 'remuneration' $(\mathrm{m}=3.81)$, followed by 'workload' $(\mathrm{m}=3.42)$. The factor which caused least stress for Qatari teachers was 'workload' $(m=2.05)$ and for non-Qatari teachers was 'lack of appreciation' $(m=2.79)$. There were no significant differences between Qatari and non-Qatari teachers in terms of total stress. However, significantly more stress was caused by 'facilities' (at .05) for Qatari than non-Qatari teachers; and significantly more stress was caused by 'workload' (at .01) for non-Qatari than Qatari teachers.

At the beginning of the school year, the factor which caused most stress for teachers in primary, preparatory and secondary schools was 'pupil problems' $(\mathrm{m}=3.80,3.85$ and 4.99, respectively), followed by 'remuneration' for teachers in primary schools $(\mathrm{m}=3.50)$, the 'curriculum' for teachers in preparatory schools $(\mathrm{m}=3.85)$ and 'low status' for teachers in secondary schools $(\mathrm{m}=3.59)$. The factor which caused least stress was 'lack of appreciation' for primary school teachers $(\mathrm{m}=2.96)$ and 'workload' for both preparatory and secondary school teachers ( $\mathrm{m}=2.85$ and 2.47 , respectively). There was no significant difference between teachers in the three different types of school in terms of total stress; however: significantly more stress was caused by 'workload' (at .01) for primary than preparatory and secondary school teachers, and for preparatory than secondary school teachers; significantly more stress was caused by 'low status' (at .05) for secondary than primary school teachers; and significantly more stress was caused by 'facilities' (at .05) for preparatory than primary and secondary school teachers.

At the end of the school year, the factor which caused most stress for teachers in primary, preparatory and secondary schools was 'pupil problems' $(\mathrm{m}=3.87,3.89$ and 4.03, respectively), followed by 'remuneration' for primary and secondary school teachers $(\mathrm{m}=3.55$ and 3.56 , respectively) and 'facilities' for preparatory school teachers $(\mathrm{m}=3.69)$. The factor which caused least stress was 'lack of appreciation' for primary school teachers $(\mathrm{m}=2.98)$ and 'workload' for preparatory and secondary school teachers $(\mathrm{m}=2.93$ and 2.48 , respectively). No significant differences were found between teachers from different types of school, in terms of total stress. However, significantly less stress was caused by 'workload' (at .01) for secondary school teachers than primary and preparatory school teachers; significantly more stress was caused by 'facilities' (at .01) for preparatory school teachers than primary school teachers; and significantly less stress 
was caused by 'safety' (at .05) for secondary school teachers than preparatory and primary school teachers.

At the beginning of the school year, the factor which caused most stress for teachers irrespective of their experience was 'pupil problems' $(\mathrm{m}=3.84,3.71$ and 4.04, respectively), followed by 'remuneration' for teachers with less than six years experience and 10 and more years experience ( $\mathrm{m}=3.65$ and 3.44 , respectively) and the 'curriculum' for teachers with six to 10 years experience $(\mathrm{m}=3.62)$. The factor which caused least stress was 'lack of appreciation' for teachers with less than six yeas experience and six to 10 years experience $(\mathrm{m}=2.98$ and 2.76 , respectively) and 'workload' for teachers with 10 and more years experience $(\mathrm{m}=2.60)$. There were no significant differences in total stress according to amount of experience. However, significantly more stress was caused by 'workload' (at .01) for teachers with 10 and more years experience than teachers with less than six years and six to 10 years experience.

At the end of the school year, the factor which caused most stress for teachers with different amounts of experience was 'pupil problems' ( $\mathrm{m}=3.88,3.88$ and 4.97, respectively), followed by 'remuneration' for teachers with less than six years experience $(\mathrm{m}=3.75)$, and the 'curriculum' for teachers with six to 10 years experience and 10 and more years experience $(\mathrm{m}=3.66$ and 3.48 , respectively). The factor which caused least stress was 'lack of appreciation' for teachers with less than six years experiences and six to 10 years experience $(m=2.96$ and 3.00 , respectively $)$ and 'workload' for teachers with 10 and more years experience $(\mathrm{m}=2.60)$. There were no significant differences between teachers with different amounts of experience, in terms of total amount of stress. However, significantly less stress was caused by 'workload' (at .01) for teachers with 10 and more years experience than teachers with less than six years experience and teachers with six to 10 years experience.

Different groups of teachers may experience different interactions with the environment as a result of different backgrounds and experiences and different roles and responsibilities in society as a result of different cultural and social expectations and environmental factors. Thus, these results are discussed in relation to cultural and social factors. Some of the results are discussed in relation to specific causes of stress; others in relation to differences within groups.

At the beginning and end of the school year 'pupil problems' was the factor which caused most stress both for all physical education teachers and for all different groups of teachers, with one exception (non-Qatari teachers at the end of the school year where most stress was caused by 'remuneration'). These results support the findings of other studies of stress in teachers in which pupils attitudes, behaviour and motivation have been found to be causes of stress (e.g. Bukhet, 
1994; Ibrahim, 1993; Mohammed, 2000; Murad, 1997; Punch \& Tuettemann, 1991; Travers \& Cooper, 1996).

One reason for this result may be that teacher's expectations of pupils' behaviour, attitudes and motivation are incongruent with actual behaviour, attitudes and motivation, or the teacher's role in enhancing pupils learning is incongruent with the actual role in dealing with pupils behaviour, attitudes and motivation. In Qatari schools, the school administration expects there to be no noise during lessons - including physical education lessons. This is difficult for physical education teachers to achieve, especially when there are a large number of pupils in a lesson. If there is noise, the teacher is seen not to be controlling pupils' well enough. This may cause stress. Further, physical education teachers are the disciplinarians in Qatari schools: they are expected not only to deal with 'pupil problems' in their own lessons, but also in the school generally. Thus, physical education teachers deal with many 'pupil problems' in any one day, week or year. Although these teachers were asked this question only in relation to physical education it may be that their responses were influenced by their overall role in the school in relation to discipline.

There may be a number of reasons why more stress was caused by 'pupil problems' for male than female physical education teachers. One reason may be different expectations and treatment of boys and girls in Qatari culture, which may make it harder for physical education teachers to deal with boys in lessons. In Qatar, boys have a significant amount of freedom and are allowed to leave home and return at any time, in most cases without needing permission. This gives them the chance to be independent. Hence, when it comes to school in general and physical education in particular, where they have to follow orders, they may find it hard to do what they are told, therefore consider it a good opportunity to misbehave. In contrast, girls have very little freedom and are not allowed to leave home without permission. Consequently, they spend most time at home and are less independent. Further, Qatari society believes that marriage is the only future for all girls (despite women being allowed to work) and there is a perception that if a girl misbehaves, it may affect their future and their marriage. On the other hand, if boys misbehave, families generally do not mind; some parents even look at it as a sign of manhood. Thus, if a girl misbehaves they are punished, whereas for the most part, boys are not punished by their families if they misbehave in schools. Thus, there is limited support/back up for teachers in disciplining boys in class.

A further cause of 'pupil problems' may be the restrictive nature of the physical education curriculum in Qatar. Indeed, the curriculum is more a series of lessons which physical education teachers are under pressure to follow - particularly as judgement of teachers performance by supervisors' is based on whether or not they are following the curriculum in detail. Most 
supervisors expect teachers to teach each lesson exactly as stated in the syllabus, rather than allowing them to be creative in preparing lessons suitable for a particular group of pupils at a particular time or for particular weather conditions. Therefore, teachers may be bored by the curriculum and lack motivation. This, in turn, may result in pupils being bored - as lessons are not interesting. Boredom may be one cause of misbehaviour. Boys have the opportunity to be active, participate in sport clubs, play football with friends, etc. outside school, therefore if lessons do not challenge boys beyond skills they have learned outside school, boredom may be exacerbated. On the other hand, for the most part, girls do not have an opportunity to participate in physical activities and sport outside school. Thus, girls may appreciate physical education lessons more than boys as, in most cases, it is the only chance they get to do physical activity/play sport and they are unlikely to have experienced the activities included in the curriculum.

Differences may also relate to the 'curriculum' causing more stress for male than female teachers at the beginning of the school year. Cultural restrictions on females, resulting in limited freedom and independence, means that there are limited opportunities for girls and women to become very proficient in physical activities. Thus, female physical education teachers generally have less background/experience in the activities in the physical education curriculum and their knowledge of physical activities is, for the most part, less than that of males. In light of their greater knowledge, the fact that the curriculum is restrictive and teachers do not have the freedom to be creative in developing their lesson content, may cause more stress for male than female teachers. Indeed, female physical education teachers may be more accepting of a curriculum that tells them what to teach.

One reason for 'pupil problems' causing more stress for non-Qatari than Qatari teachers could be that pupils show more respect to Qatari teachers than to those of non-Qatari nationality. At the same time, non-Qatari teachers are on a contract that can be terminated at the end of the school year, therefore have no secure future. There may even be the risk of a teacher losing his/her job if there are any complaints from pupils about that teacher. Consequently, non-Qatari teachers may avoid disciplining pupils, even if pupils misbehave. On the other hand, the future for Qatari physical education teachers is secure and they are able to discipline pupils without fear of losing their jobs.

'Low status' also caused significantly more stress for male than female teachers. This difference may be partly explained by cultural factors, including the status and perceived roles of males and females in Qatari society. This, in turn, influences the status of teaching in general and physical education in particular. Teaching is not considered a highly prestigious job for males, with the teaching of physical education having even less prestige. Males in Qatari society have 
greater opportunity to work in a wider range of jobs than females - many of which have higher status and are better remunerated and are perceived to incorporate more development and growth opportunities than teaching. Thus, many males in Qatar do not want to teach because of the low status and low salary. This is witnessed by the low number of males applying to study physical education at Qatar University as their first choice. Many males apply for courses which lead to professions such as engineering or medicine which are seen to have more status than teaching, but, if unsuccessful, they then apply to study physical education. On the other hand, although it is optional for women to work in Qatar, they are not precluded from holding good positions. If a woman does work, religious and cultural standards mean that it is better if she works in an all female environment, and does not mix with men during work. In Qatar all schools are single sex and, with the exception of female teachers in boys primary schools, teachers are the same gender as the pupils in the school. Thus, teaching is a very acceptable profession for women in comparison with other jobs because they are working in an all-female environment. Thus, teaching is popular for females and for most females, physical education is their first choice of career. Thus, all places for females in physical education at Qatar University are taken, whilst not all those for males are taken. This has resulted in more female than male physical education teachers having graduated from Qatar University every year over the last 10 years or so, whereas prior to that more male physical education teachers graduated.

Stress caused by 'low status' may be exacerbated for male teachers who teach in secondary schools - who are generally more experienced as teachers. Qatari society views teachers of other subjects with greater respect, valuing their contribution to the educational process more highly than that of physical education teachers - especially at secondary school level. There is greater focus on, and parents are also more concerned with, examinations and examination results in secondary schools. Pupils therefore tend not to pay as much attention to physical education lessons as they do to other subjects. Rather, they tend to consider physical education a time to have fun and play, as there is no pass or fail in this subject. Further, parents might see the value of physical education for pupils as a break from academic subjects, hence value physical education less than they do other subjects and less than physical education at the primary and preparatory school levels. Thus, pupils and their parents do not see physical education as a serious subject; thus pupils may not bring their kit to class, or behave well in class. If the physical education teacher tries to follow this up, pupils and their parents do not take the teacher seriously. Thus, 'pupil problems' in physical education in Qatar could also be related to 'low status'.

'Low status' may also be related to remuneration. Qatar is a wealthy country and teachers 'remuneration' is generally good (indeed better than in most other Middle Eastern countries, which 
is the main reason that many non-Qatari teachers work in Qatar). However, 'remuneration' was ranked high in relation to stress overall and for some groups of teachers. One reason for this in relation to Qatari teachers could be that physical education teachers in Qatar are remunerated less than teachers of other subjects. This is because the Ministry of Education and Higher Education offers higher remuneration to teachers of other subjects to attract Qatari nationals to work as teachers and to motivate them to stay. Also, teachers of other subjects are able to run study groups/teach pupils privately, therefore are able to supplement their 'remuneration' from school. Thus, differences between physical education teachers and teachers of other subjects may, at least partly, account for 'remuneration' being rated second as causes of stress.

Further, teachers receive lower remuneration than those working in other professions. Male secondary school physical education teachers in particular are likely to see the salary of friends in other professions having increased more quickly than theirs, giving them higher status. The link between status and salary is shown by the example of police and the army. In the 1970s in Qatar the status of policemen and the army was very low; therefore they did not attract many recruits. One major reason for this was that remuneration was low compared to other jobs. However, the government solved this problem by giving higher remuneration. This resulted in the police and army now having a very good status in Qatar and these two jobs are now perceived positively, as witnessed by the increased number of applicants for posts.

'Remuneration' caused significantly more stress for non-Qatari than Qatari teachers at the beginning of the school year. This may be because although salaries in Qatar for non-Qatari teachers are higher than salaries in other Middle Eastern countries, non-Qatari teachers receive lower salaries than Qatari teachers.

Thus, stress due to 'remuneration' may not have so much to do with the actual amount of remuneration but a misfit between perceptions of appropriate 'remuneration' in light of other factors (e.g. what teachers of other subjects and people working in other professions are paid) and what physical education teachers are actually paid.

'Workload' was ranked low as a cause of stress. 'Workload' caused significantly more stress for female than male teachers. In a working day, which runs from 7.00 a.m. to 1.30 p.m., neither male nor female physical education teachers in Qatar teach a large number of classes. However, female teachers have higher workloads than male teachers. There are fewer physical education teachers in girls' than in boys' schools. Further, although boys have more physical education lessons than girls, female physical education teachers teach more lessons than male teachers. Male teachers teach, on average, one lesson of 40 minutes per day and female teachers teach, on average, two lessons each of 40 minutes per day. Furthermore, this result could be due to 
the fact that female physical education teachers have more responsibilities outside school than male physical education teachers, e.g., responsibilities regarding husband and children. Thus, the 'workload' in school, alongside those of home and family, may add to the perceptions by women of significantly more stress caused by 'workload' than males.

'Workload' also caused significantly more stress for primary than preparatory and secondary school teachers, and for preparatory than secondary school teachers at the beginning of the school year. One reason for this could be that most primary school teachers have less experience than teachers in preparatory and secondary schools, and preparatory school teachers have less experience than secondary school teachers. Thus, they are learning how to cope with their work, which may result in perceptions of having more work to do. In addition, in primary schools, physical education teachers teach more lessons than their preparatory and secondary school counterparts. As they gain experience it would be expected that teachers are able to handle the 'workload' better. This finding is substantiated by significant differences both at the beginning and end of the school year between physical education teachers with different amounts of experience in relation to 'workload'. 'Workload' caused less stress for teachers with 10 and more years experience than teachers with less than 10 years experience. This result is similar to Khaleel (1999), who indicated that physical education teachers with less than 6 years experience experienced more stress than teachers with more experience.

However, the finding is contradicted somewhat by the result that although 'workload' caused significantly more stress for Qatari than non-Qatari teachers at the beginning of the school year, it caused significantly more stress for non-Qatari than Qatari teachers at the end of the school year. Non-Qatari teachers, as a group, have more experience than Qatari teachers, thus it would be anticipated that they would be able to cope better with the 'workload' of the job. However, although teaching loads are light, physical education teachers in Qatar have additional responsibilities unrelated to their primary position as physical education teachers (e.g. discipline across the school), but which most physical education teachers believe are just part of their job as physical education teachers. One reason for this may be because the Ministry of Education and Higher Education has not clearly defined the role of a physical education teacher. Another reason may be because physical education teachers from other Arab countries who started teaching in Qatar in the 1980's undertook whatever responsibilities the school administration asked them to do, even when it was not related to their role as physical education teachers. This was mainly because they were working on a one year contract and they wanted to do everything they could in order for the contract to be renewed. This set a precedent. As the number of Qatari physical education teachers increased during the 1990's, they simply continued to do what the non-Qatari 
physical education teachers had done. Non-Qatari teachers continue to be employed on yearly contracts. Although both Qatari and non-Qatari teachers take on these additional responsibilities, the worry of whether or not their contract will be renewed for the following year, may result in non-Qatari teachers carrying a heavier load by undertaking any task required by the school. Thus, 'workload' may be accumulative throughout the year, which may account for significantly more stress at the end of the school year for non-Qatari than Qatari teachers.

\section{CONCLUSION}

In summary, there are no significant differences in stress at the beginning and end of the school year for physical education teachers in Qatar. However, the picture is more complicated because, when analysed by gender, nationality, type of school in which work and amount of experience as a teacher, significant differences begin to emerge between groups. These results suggest differences between different groups may result in them interacting differently with their environment. This may be due to different backgrounds and experiences and different roles and responsibilities in society as a result of different cultural and social expectations and environmental factors.

These results identify factors in relation to causes of stress for physical education teachers. Another study should compare causes of stress for physical education teachers in Qatar with causes of stress for teachers of other subjects to see whether any misfit with the environment for teachers of other subjects is a result of similar factors. For example, it should look at whether teachers of other subjects experience a similar misfit with the environment in relation to 'pupil problems'. This may help to identify whether the misfit for physical education teachers is partly due to the broader role which physical education teachers undertake in Qatari schools in relation to discipline. Likewise, it should look at whether the curriculum is a cause of stress. This may help to identify whether there is a misfit between expectations of physical education teachers to deliver a series of lessons in a set order in a specific way and their ability to adapt content, teaching style and approach to particular circumstances (including the group of pupils, the facilities and the weather) or between the requirements of delivering the curriculum and knowledge for teaching or whether this is common across subjects.

Finally, although this study suggests that different backgrounds and experiences and different roles and responsibilities in society as a result of different cultural and social expectations and environmental factors may result in different groups interacting differently with their environment - these results do not account for differences between individuals. No two people are the same, therefore not all people in one group will respond in the same way. This study did not 
look at differences between individuals. Another study is therefore needed to look at differences between individuals within these groups to determine specific factors for each person that cause a fit or misfit between an individual and the environment. This should bring out more personal factors as well as those related to teaching and the conditions of work, as identified in this study. 


\section{REFERENCES}

Abel, M.H. \& Sewell, A.J. (1999) Stress and burnout in rural and urban secondary school teachers. The Journal of Educational Research, May/June, 92 (5), 287-293.

Adams, E. (2001) A proposed causal model of vocational teacher stress. Journal of Vocational Education and Training, 53 (2), 223-246.

Al-farmawy, H.A. (1994) The teacher's stress level. Paper presented at the Second Egyptian Education Summit.

Al-khalefa, S.M. (1999) Female PE teacher stress in primary schools in the Kingdom of Bahrain. Unpublished PhD Dissertation, Physical Education College in AL Harem, Cairo, Egypt.

Blix, G.B., Cruise, R.J., Mitchell, B.M. \& Blix, G.G. (1994) Occupational stress among university teachers. Educational Research, 36, 57-169.

Borg, M., Riding, R. \& Falzon, J (1991) Stress in teaching: A study of occupational stress and its determinants, job satisfaction and career commitment among primary schoolteachers. Educational Psychology, 11, 59-75.

Brown, M. \& Ralph, S. (1992) Teacher stress. Research in Education, 48, 103-110.

Brown, M. \& Ralph, S. (2002) Teacher stress and school improvement. Improving Schools, 5 (2), 55-65.

Bukhet, M. (1994) Stress and its relation with self improvement. Unpublished MA Thesis, Ain Shames University, Cairo, Egypt

Caplan, R.D. (1987) Person-environment fit theory and organisation: Commensurate dimensions, time perspective and mechanisms. Journal of Vocational Behaviour, 32, 248-267.

Caplan, R.D. \& Harrison, R.V. (1993) Person-environment fit theory, recent development and future directions. Journal of Social Issues, 49, 253-76.

Cooper, C.L. (ed) (1996) Handbook of stress and health. Florida: CRC Press.

Cooper, C.L. \& Kelly, M. (1993) Occupational stress in headteachers: A national UK study. British Journal of Educational Psychology, 63, 130-43.

Dick, R.V. \& Wagner, U. (2001) Stress and strain in teaching: A structural equation approach. British Journal of Educational Psychology, 71, 243-259.

Dunham, J. (1976) Stress situations and responses. In National Association of Schoolmasters (Ed.) Stress in schools. Hemel Hempstead, Herts: National Association of Schoolmasters.

Dunham, E. (1984) Stress in teaching. London: Croom Helm.

Fejgin, N., Ephraty, N. \& Ben-Sira, D. (1995) Work environment and burnout of physical education teachers. Journal of Teaching in Physical Education, 15, 64-78.

French, J.R.P., Caplan, R.D. \& Harrison, R.V. (1982) The mechanisms of job stress and strain. London: Wiley.

Harrison, R.V. (1985) The Person-environment fit model and the study of job stress. In T.A. Beehr \& R.S. Bhagat (eds) Human stress and cognition in organizations. New York: Wiley, pp. 23-55.

Harrison, R.V. (1978) Person-environment fit and job stress. In C.L. Cooper \& R. Payne (eds) Stress at work. New York: Wiley, pp. 175-205.

Hart, P.M., Wearing, A.J. \& Conn, M. (1995) Conventional wisdom is a poor predictor of the relationship between discipline policy, student misbehaviour and teacher stress. British Journal of Educational Psychology, 65, 27-48.

Ibrahim, S.I. (1993) Stress for male and female PE teachers. Unpublished Master thesis, Education College, Al Zagazig University, Al Zagazig, Egypt

Jones, F. \& Fletcher, B.C. (1999) Occupational stress. In D. Messer \& K. Jones (eds) Psychology in social care. London: Jessica Kingsley.

Khaleel, S. (1999) Building a measure for stress and burnout for physical education. Unpublished $\mathrm{PhD}$ dissertation, Al Zagazig University, Al Zagazig, Egypt. 
Kyriacou, C. (1989) The nature and prevalence of teacher stress. In M. Cole \& S. Walker (eds) Teaching and stress. Milton Keynes: Open University Press.

Kyriacou, C. (1987) Teacher stress and burnout: An international review. Educational Research, 29, 146-152.

Kyriacou, C. \& Sutcliffe, J. (1987a) A model of teacher stress. Educational Studies, 4, 1-6.

Kyriacou, C. \& Sutcliffe, J. (1987b) Teacher stress and satisfaction. Educational Research, 21 (2), 89-96.

Kyriacou, C. \& Sutcliffe, J. (1978) Teacher stress: Prevalence, sources and symptoms. British Journal of Educational Psychology, 48, 159-167.

Kyriacou, C. \& Sutcliffe, J. (1977) Teacher stress: A review. Educational Review, 29 (4), 299306.

Lazarus, R. (1966) Psychological stress and the coping process. New York: McGraw-Hill.

Lazarus, R.S. \& Folkman, S. (1984) Stress appraisal and coping. New York: Springer.

Manthei, R. \& Solman, R. (1988) Teacher stress and negative outcomes in Canterbury state schools. New Zealand Journal of Educational Studies, 23, 145-163.

Mohammed, M.A. (2000) Teacher stress. Unpublished dissertation Physical Education College in Cairo.

Murad, S. (1997) Stress for teachers. Education College Magazine, No 29, Al Zagazig University, Al Zagazig, Egypt.

Pithers, R.T. \& Fogarty, G.J. (1995) Symposium on teacher stress: Occupational stress among vocational teachers. British Journal of Educational Psychology, 65, 3-14.

Pithers, R.T. \& Soden, R. (1998) Scottish and Australian teacher stress and strain: A comparative study. British Journal of Educational Psychology, 68, 269-279.

Proctor, J. (1994) Occupational stress among Grampian primary teachers. Education in the North, New Series, 2, 46-54.

Punch, K.J. \& Tuettemann, E. (1991) Stressful factors and the likelihood of psychological distress among classroom teachers. Educational Research, 33 (1), 65-69.

Quick, J.C. \& Quick, J.D. (1984) Organisational stress and preventative management. New York: McGraw- Hill

Reid, G. \& Hinton, J. (1999) Teacher work stress and school organisation: A suitable case for INSET. Education Today, 49 (4), 30-37.

Selye, H. (1946) General adaptation syndrome and diseases of adaptation. Journal of Clinical Endocrinology, 6.

Smith, M. \& Bourke, S. (1992) Teacher stress: Examining a model based on context, workload and satisfaction. Teaching and Teacher Education, 8 (1), 31-46.

Storey, J. \& Billingham, J. (2001) Occupational stress and social work. Social Work Education, 20 (6), 659-670.

Tollan, J.H. (1990) 'Stress aid': An evaluation of the effectiveness of a whole school approach to stress in prevention in ameliorating occupational stress in primary school teachers in one Scottish Region. Unpublished MSc thesis, University of Stirling.

Travers, C. \& Cooper, C. (1996) Teachers under pressure: Stress in the teaching profession. London: Routledge.

Trendall, C. (1989) Stress in teaching and teacher effectiveness: A study of teachers across mainstream and special education. Educational Research, 31, 52-59.

Tuettemann, E. \& Punch, K.F. (1990) Stress levels among secondary school teachers. Educational Review, 42 (1), 25-29.

Wilson, V. \& Hall, J. (2002) Running twice as fast? A review of the research literature on teachers' stress. Scottish Educational Review, 34 (2), 175-187. 
Table 1: Differences between the stress factors at the beginning and end of the academic year for physical education teachers

\begin{tabular}{|l|l|l|l|l|l|l|}
\hline \multicolumn{1}{|c|}{ stress factors } & \multicolumn{2}{c|}{$\begin{array}{c}\text { Beginning of the } \\
\text { academic year }\end{array}$} & \multicolumn{2}{c|}{$\begin{array}{c}\text { End of the academic } \\
\text { M }\end{array}$} & \multicolumn{1}{|c|}{ SD } & \multicolumn{2}{c|}{ M } & \multicolumn{2}{c|}{ Tear } \\
\hline $\begin{array}{l}\text { Problems with } \\
\text { administration (F1) }\end{array}$ & 2.89 & .70 & 2.93 & .82 & .72 & .471 \\
\hline $\begin{array}{l}\text { Workload and } \\
\text { responsibilities (F2) }\end{array}$ & 2.82 & .76 & 2.94 & .85 & 2.03 & $.044 *$ \\
\hline $\begin{array}{l}\text { physical education } \\
\text { curriculum (F3) }\end{array}$ & 3.51 & .67 & 3.61 & .75 & 1.56 & .121 \\
\hline $\begin{array}{l}\text { Low status of physical } \\
\text { education (F4) }\end{array}$ & 3.36 & .77 & 3.42 & .82 & 1.10 & .274 \\
\hline $\begin{array}{l}\text { Salaries, bonuses and } \\
\text { allowances (F5) }\end{array}$ & 3.44 & 1.13 & 3.57 & 1.04 & 1.47 & .144 \\
\hline \begin{tabular}{l} 
Poor school facilities (F6) \\
\hline
\end{tabular} & 3.44 & .81 & 3.50 & .83 & .82 & .415 \\
\hline $\begin{array}{l}\text { Pupils' problems (F7) } \\
\text { pupils' safety (F8) }\end{array}$ & 3.92 & .89 & 3.90 & .82 & .16 & .869 \\
\hline Total & 3.29 & .71 & 3.29 & .82 & .06 & .950 \\
\hline
\end{tabular}

\begin{tabular}{|l|}
\hline$*$ Sig. at level 0.05 \\
\hline$* *$ Sig. at level 0.01 \\
\hline
\end{tabular}

